\title{
Changing Patterns of Commercial Sex Work Amongst Adolescent Girls in Nepal: The Role of Technology
}

\author{
Anita Ghimire $^{1}$ (D) Fiona Samuels $^{2} \cdot$ Sarmila Mainali $^{1}$
}

Accepted: 9 August 2021 / Published online: 30 August 2021

(C) The Author(s) 2021

\begin{abstract}
The introduction of technology, particularly mobile phones, in the mediation of commercial sex work (CSW) has meant that sex work is expanding from traditional venue based (such as through hotels and massage parlors) work to freelance sex work. It has also changed the face-to-face negotiation in commercial sex work to negotiations mediated online or by phone. Apart from a few programmes, interventions largely use establishments as entry points for their programming and are therefore excluding many girls and women who engage in CSW through personal contacts or facilitated by social media. This article is based on a two-year qualitative study in four districts of Nepal, in Delhi (India), and the Indo-Nepal border in eastern Nepal. It gives a short overview of the girls and their life in the adult entertainment sector (AES), which is the main entry point for CSW, and discusses how technology is increasingly used to mediate CSW. Based on our findings, which show that technology is displacing establishment-based CSW in Nepal, we argue that to ensure that we do not leave girls behind, programmes and interventions targeting venues where girls engage in CSW should re-consider their strategies for reaching girls working in the AES.
\end{abstract}

Keywords Adolescents · Nepal · Commercial sex work · Adult entertainment sector $\cdot$ Technology $\cdot$ Social media $\cdot$ Trafficking

\section{Résumé}

Avec l'utilisation de la technologie dans le cadre du commerce du sexe (CSW), en particulier des téléphones portables, le travail du sexe ne se cantonne plus au travail traditionnel lié à des établissements précis (tels que les hôtels et les salons de massage) et s'élargit au travail du sexe indépendant. Cela a également changé les modes de négociation dans le commerce du sexe, en passant de la négociation en face-à-

Anita Ghimire

bhattarainitu@gmail.com

1 Nepal Institute for Social and Environmental Research, Lalitpur, Nepal

2 Overseas Development Institute, London, UK

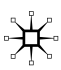


face à des négociations en ligne ou par téléphone. Hormis quelques programmes, les interventions ciblent largement les établissements comme points d'entrée de leur programme et excluent par là de nombreuses filles et femmes qui s'engagent dans le commerce du sexe par le biais de contacts personnels ou grâce aux médias sociaux. Cet article est basé sur une étude qualitative de deux ans dans quatre districts du Népal, à Delhi (en Inde) et à la frontière indo-népalaise dans l'est du Népal. Il fournit un bref aperçu des filles et de leur vie dans le secteur du divertissement pour adultes (AES), le principal point d'entrée pour le commerce du sexe, et explique comment la technologie est de plus en plus utilisée pour permettre le commerce du sexe. Sur la base de nos résultats, qui montrent que la technologie permet au commerce du sexe d'avoir lieu en dehors des établissements traditionnels au Népal, nous soutenons que, pour nous assurer de ne laisser aucune fille de côté, les programmes et les interventions ciblant les établissements où les filles participent au commerce du sexe devraient reconsidérer leurs stratégies pour atteindre les filles travaillant dans le secteur du divertissement pour adultes.

\section{Introduction}

Like many other developing countries, Nepal has a 'youth bulge', whereby $63.7 \%$ of its 26.5 million people are below the age of 30 (Basnett et al. 2014). The youth unemployment rate $(19.2 \%)$ is much higher than that of the general working-age population (15-64 years of age) (3.3\%) (CBS 2019). Slow pace structural economic transformation has meant that there are limited/no industries to absorb labour; similarly opportunities to shift employment from subsistence agriculture where incomes are low, to industry and manufacturing sectors where incomes are better, are almost non-existent. This has meant that youth have not been able to engage in high earning sectors. Additionally, young people entering the labour market often do not have skills and experience required for the few jobs that give them the ability to earn a higher income. While there is no data on the proportion of adolescents (aged 10-19) in agriculture, it contributes to the employment of almost $75 \%$ of Nepal's total population (Raju and Rajbhandari 2018). Of the total employed population, $62 \%$ of people work in informal jobs (if we do not count agricultural labour), rising to $96.2 \%$ if we include the agricultural sector (CBS 2019). Agriculture is still predominantly traditional and not seen as a desirable occupation for the current generation of adolescents, who are the most educated generation the country has had (Serriere and CEDA 2014). As a result, they often abandon rural areas to work outside agriculture (Paudel et al. 2014).

International migration, primarily to Malaysia and Gulf countries, absorbs a significant proportion of young people: according to a report by the International Organization for Migration (IOM), $47 \%$ of Nepalis who migrated overseas were aged 18-29 years (de Zwager and Sintov 2017). However, not all people can migrate internationally for work for various reasons, including poverty. This often leads to internal migration, usually to urban areas, where the jobs available to them are often in the informal sector such as daily wage labour in small hotels and construction sites (Serriere and CEDA 2014). 
This study looks at one of these types of work-commercial sex work (CSW) among adolescent girls and young women. While international literature on use of technology in CSW is growing (Campbell et al. 2018; Cunningham and de Angelo 2017, MacPhail et al. 2015; Scott et al. 2015; Cunningham and Kendall 2011), there is a dearth of such literature on Nepal. This article aims to help fill this gap by discussing how technology is changing the nature and patterns of CSW among adolescents and young women (aged up to 25 years), based on findings from the Gender and Adolescence: Global Evidence (GAGE) study.

\section{Commercial Sex Work in Nepal: A Review of the Literature}

Commercial sex work (CSW) is largely associated with the adult entertainment sector (AES) in Nepal which is comprised of hotels, massage parlours, spa, dance bar, clubs, guest houses, singing bars- "Doharis" and street based CSW venues. While CSW does not necessarily happen in all these venues, they are an important platform for initial contact, networking and negotiation between the girls and potential clients. Similarly, it is also important to note that not all people who work in the AES necessarily engage in CSW and AES venues do not necessarily sell sex. Traditionally, CSW was provided by a few small informal liquor shops ('bhatti pasal') operated by sex workers themselves along the east-west highway of Nepal, while a few women engaged in street-based sex work; clients largely consisted of transportation sector workers (Frederick et al. 2010). Socioeconomic changes in the 1980s in Nepal, largely resulting from increased industrialisation and globalisation, increased CSW, particularly in the Kathmandu valley where people migrated to work in carpet and garment industries.

In the 1990s, CSW expanded considerably, especially after Nepal adopted liberal economic policies (NHRC 2010). Considerable investments made by local businessmen in infrastructure and establishments associated with the AES, such as hotels, dance bars, clubs, massage parlours and guest houses, also enabled the proliferation of CSW (Dank et al. 2019; Risal et al. 2018; Frederick et al. 2010; Shakti Samuha 2008; CREHPA 2001). While traditional "bhatti Pasal" which sold sex were largely owned and run by women sex workers themselves, $80 \%$ of owners of the AES businesses now are men (Shakti Samuha 2008).

The AES in Nepal spreads across urban areas throughout the country and particularly in cities such as Kathmandu, Jhapa, Pokhara and Dharan, and pockets along the country's east-west highway (Dank et al. 2019). While men and women both work in the sector, the jobs they do are different: men largely work in management or as cooks, waiters, drivers, or guards, while women mostly entertain clients (Risal et al. 2018; Safer Migration Project (SaMi)/HELVETAS Swiss Intercooperation Nepal 2018). Estimates of the number of men, women and children involved in the sector are outdated and vary from 11,000 to 40,000 . Since the work is stigmatised in Nepal, it tends to remain hidden thus accounting for these differences in the estimates. According to Terre des Hommes, in 2010, in Kathmandu alone, there were between 11,000 and 13,000 girls and women working in the AES. The Nepali 
government's estimate around the same time was between 30,000 and 40,000 girls and women (Ministry of Women, Children and Social Welfare 2008).

While there is no specific data on adolescents working in the AES, most studies find that the age of entry into AES work is below 18 years for girls (Dank et al. 2019; CWIN and ECPAT 2015; Frederick et al., 2010). A recent study for instance, conducted among 600 girls working in the AES sector in Kathmandu, showed that their average age was 17.5 years and the average age of entry into AES work was 15 years (Risal et al. 2018). Another found that minors (those below 18 years) constituted $33 \%$ of all those working in the AES in Kathmandu (Shakti Samuha 2008). A later study identified around 1,650 minors (17\% of the workers) engaged in the AES (and specifically CSW) in Kathmandu alone; most respondents (47\%) had entered this sector (the AES) between the ages of 15 and 17, while $37 \%$ had entered between the ages of 18 and 21 (Dank et al. 2019). These studies show that girls are most likely to enter the AES under the influence of their peers and other social networks, are largely not trafficked into the sector but might end in situation of trafficking later and most enter during mid or old adolescence, rather than as children.

Working conditions in the AES are often exploitative and several studies show evidence of physical and psychosocial abuse, stigma, health/sexual and reproductive health related problems, drug and alcohol abuse, and girls being coerced into sexual activities. According to Dank et al. (2019), in their survey of 600 Nepali girls working in the AES in Kathmandu valley, a quarter were forced into drug abuse, $27 \%$ were forced into situations of forced labour and $60 \%$ had to work in sexually exploitative conditions. Additionally, those working in the AES rarely have job contracts or any of the rights that accompany work in the formal sector (ibid).

While the AES work is legal in Nepal, Nepal's law does not recognise CSW. Police arrest commercial sex workers under the broader allegation of disrupting social harmony which is illegal in Nepal. If minors are involved in the AES, the employers are penalised for illegal child labour, sexual exploitation and trafficking.

Nepal's government, donors, national and international non-government organisations (NGOs), have all been working for more than a decade to assist those working in the AES to find other means of livelihoods, to end exploitation, provide legal support and protection from violence, and resolve sexual and reproductive health (SRH) problems related to this type of work (such as sexually transmitted illnesses [STIs]).

Internationally, there is plentiful literature on the relationship between technological advancement and changes in the structure and organisation of sex work. Studies in the UK show that online advertisement of sex work started there as early as in the 1980s (e.g. Cunningham and Kendall 2011). Other studies show that penalties associated with sex work (street-based sex work in particular) along with the gentrification of areas historically associated with sex work, when combined with technological advancement, resulted in the sex trade being mediated digitally. This included, for instance, sex work provided and facilitated through platforms such as web-cameras, emails and chatrooms (Campbell et al. 2018; Cunningham and de Angelo 2017; MacPhail et al. 2015; Scott et al. 2015; Cunningham and Kendall 2011). These studies also found that this digitalisation of sex work represents both 
a large expansion in the overall market for sex work, but also a partial displacement of the establishment-based and street-based sex work to more contact and networkbased sex work, particularly for women in the 30-40 years age group (Cunningham and de Angelo 2017).

Some studies (Rand 2019; Sanders et al. 2016) that explored the lives of men and women engaged in online CSW have focused on levels of control over working conditions, prices, clientele and services sold, the process of online facilitation and safety issues. There is mixed evidence around how protective online sex work is for the sex workers. Some literature (e.g. Sanders et al. 2016; Cunningham and Kendall 2011) finds that the internet may provide a safer work environment for sex workers observing that there is a lower risk of theft or blackmail, including through client screening websites; others (e.g. Jones 2015) have argued that this is too optimistic and paints a homogenised picture of people who solicit digitised sex work.

International literature around adolescents and technology use is largely concentrated in high income countries and in some parts of Africa (see Livingstone et al. 2017). Studies have explored internet access, agency in using the internet, digital skills and patterns of use, opportunities and outcomes, as well as how digital technology is used for education and information (Ibegbulam et al. 2018; Zelezny-Green 2018) and for building identity and social relationships and sexual negotiations by adolescent girls (Onyima and Egbunike 2019). There are also an array of studies exploring the impact of technology usage on psychosocial wellbeing, health and violence (e.g. Carson et al. 2018; Stonard et al 2014).

As discussed earlier, literature on CSW in Nepal largely focuses on involvement of minors in the AES (Dank et al. 2019; Risal et al. 2018; Frederick et al. 2010; Shakti Samuha 2008), international trafficking (Safer Migration Project (SaMi)/ HELVETAS Swiss Intercooperation Nepal 2015), reintegration challenges and protection of women trafficked to India (Richardson et al. 2016; Maiti Nepal 2010; Poudel and Luintel 2003). Apart from studies conducted recently by the Freedom Fund (2018, 2019), the use of technology in mediating CSW have not been explored in any depth. There are no specific programmes targeting adolescents working in the AES or involved in CSW. Most programmes that work for the protection of women and girls working in the AES, focus on establishment-based CSW or street based sex work. As also indicated in the literature from outside Nepal, it is critical to understand the role of technology in changing how CSW is organised and structured and to adapt interventions accordingly, as well as involving users (including adolescents) in their design.

\section{Methodology}

This article is based on two rounds of primary data collection carried out between 2018 and 2020, in five areas: Kathmandu, the hub for the AES; Sindhupalchowk, a district of origin for many girls and boys working in the AES in Kathmandu; Delhi, India, as a destination for girls working in the AES; and two districts in Nepal recommended by key informants where the AES is on the increase, Jhapa and Sunsari. Key informant interviews (KIIs) with organisations and government representatives 
engaged in policy and programming on trafficking and the AES, were carried out first. These was then followed by a first round of data collection in Kathmandu, Sindhupalchowk and Delhi, and second round in Kathmandu, Jhapa and Sunsari (following up particularly on issues related to technology use).

We explored girls and boys working in different AES venues-dance bars, discos, massage parlours, home-based and street-based sex workers, freelance sex workers, and those working in guest houses. The limitation of the article is that we focus largely on findings related to girls even when they come from interviews with boys. This is because we were unable to interview boys who said they were involved in CSW. Data from interviews with boys are used to give boys perspectives on girls; we indicate in the text where information comes from boys. For the findings this will mean that there will be no comparative evidence for boys.

\section{Research Design}

Appendix gives details of the research design. Twenty-six focus group discussions (FGDs) were conducted with girls and boys working in different types of AES venues in the study sites, men, women and adolescent boys and girls of the community of origin, and boys working in Delhi. Forty in-depth Interviews (IDIs) were conducted with girls and boys working in the different AES establishments and as freelance sex workers. Forty-five key informant interviews (KIIs), three case studies with girls rescued from engaging in the international AES and now living in shelter homes and girls who left the AES to work in non-AES sector and nine life history interviews were conducted. Respondents were identified through snowball methods starting with mapping of stakeholders engaged in policy and programming around the AES.

The research team, with the help of a local facilitator, also observed two Nepal/ India border crossing checkpoints known to be trafficking routes for the AES in India and beyond (e.g. the Gulf states). The border points were observed for three days at each point. A structured information template was developed for observation and points were noted for each of the themes observed (which included how and with whom girls cross the border, how they come to the border points and the procedures they have to go through to cross the points among others).

The team further analysed 10 intervention programmes working with people engaged in the sector; programmes were selected with support from on KIIs. Criteria for programme selection include those that were currently running, had large numbers of girls and women participants and had interventions that cover a combination of areas (life-skills, livelihoods, education support, SRH, psychosocial counselling, etc.).

An online study of social media (including Facebook, Messenger, IMO, YouTube and a digital TV channel, Pulcowki Media, Masti Talk time) was also conducted. Social media analysis was done after the KIIs in the second year. The team leader and a designated research assistant became members of networks in selected social media groups (e.g. IMO) and followed them on Facebook. Interactions and information exchanges were observed and noted regularly. Data collected included what 
activities took place in IMO, most active people/content and types of conversations (e.g. private smaller groups versus exchanges across all group members). We also analysed video and interview content of a popular Nepali AES site on YouTubethe Phulchowki Media-for three months. The site was introduced to us by one of our key informants. We looked at the contents of the interviews, as well as conducted further searches on the interviewees to access relevant information about online sex work (such as accessing their personal YouTube channels). However, after three months, the government of Nepal banned the channel and deleted all the content. The YouTube channels of the interviewees were also deleted along with other online information that were deemed pornographic; therefore the analysis was stopped.

\section{Research Ethics and Access to Respondents}

Respondents were identified through three NGOs implementing programmes for commercial sex workers (Rakhsya Nepal, Biswas Nepal and the Women Workers' Protection Union). The NGOs were selected based on our previous work experience in the AES (Rakshya Nepal) and those that had multiple interventions. All three NGOs partners were given similar criteria by which to select the respondents, i.e. they had to be adolescent girls who belonged to different venues of the AES, freelance and street based sex work and those who were happy to speak with us in absence of the partner NGO staffs. They were careful to select girls and boys who were willing to talk to us and who did not appear to have been traumatised by their experiences. This may have influenced the study findings, with the research team possibly speaking to the more vocal individuals among potential respondents. Once a set of respondents had been identified, we also asked the girls to connect us with their friends who were not in contact with the partner NGOs but were willing to speak with us. This was to ensure that we captured diversity among respondents. All ethical protocols were followed: girls were informed about the study objectives, assured that all information will be anonymised, that speaking to us would not affect access to services, that they were free to stop the interview at any time and/or choose not to answer a question if they felt uncomfortable. If they agreed, we would make a follow up call and ask if they were happy to speak to us. This would be followed by meeting in person and seeking formal consent again reiterating the above-mentioned conditions. Written consent was taken by partner NGOs in case of minors.

Interview venues were either the offices of the NGOs, hotels or other venues suggested by respondents. For case studies, we also visited the girls' current place of residence and/or workplace. We ensured that staff from NGOs who helped us with the study were not present during the interviews or group discussions so that respondents could talk freely and so that NGO staff could not influence the direction of the discussions and interviews.

Ethical approval was given by the internal review board (IRB) of the Nepal Institute for Social and Environmental Research (NISER), the three NGOs partners and the central and local government entities. 
We also followed existing procedures and protocols for carrying out research amongst children and adolescents including, UNICEF's (Powell et al 2013) Ethical Research Involving Children. If members of the research team felt there were aspects of the study they found difficult to hear-they were not required to probe further as per NISER's ERB guidelines. Except for one instance where one respondent was suffering from fever and still turned up for interview, we did not face any ethical concerns. For safeguarding and reporting of potential violence, a respondent safeguarding protocol was in place in case of need which included a safeguarding focal person and safeguarding arrangement with the three partner NGOs. There were no instances where girls asked us for help regarding violence. They asked us for financial help or help in getting a job and we had made it clear during the consent seeking process that the research would not be able to provide financial or material help, or help in getting jobs.

\section{Data Collection and Analysis}

Interviews were recorded with consent. Each respondent was given lunch and an additional transportation cost (US \$4.40). This was a fixed amount based on discussion with the relevant partner NGO and the information about the transportation allowance was shared during the initial contact period before the interviews.

The interviews were transcribed and translated into English by the researchers who had conducted the interviews. Translation and transcription followed the GAGE translation and transcription format an, protocol and was supervised by the team leader. Names and other factors that could reveal the respondent's identity were changed. The anonymised transcripts were coded using MAXQDA software. A draft codebook was developed by the team lead and approved by the country research team leader. Coding was done by team members who collected the data.

\section{Findings}

\section{Context Setting: The Adult Entertainment Sector in Nepal and Venues for Commercial Sex Work}

Our research suggests that mediation in CSW is moving from face-to-face to the virtual world. Many girls who had previously been working in establishments have now started working on their own. The study finds that there are two reasons for this. First, since 2018, rules around the penalties for CSW have changed. While CSW is unrecognised in Nepal, the government carries out monitoring in AES venues and can penalise CSW under anti-social behaviour, trafficking and child labour legislation. Previously, girls would be arrested and fined-not the employer who runs the establishment/work or the client. However, according to the new law in 2018, if CSW-related activities are found in any establishment, the owner(s) can be imprisoned for 10 years and has to pay a large penalty. This has meant that establishment 
owners now refrain from employing such girls as full-time workers and only link girls with clients when clients so demand, while taking commission for doing so.

Second, the proliferation of phones, internet and social media has led to a decrease in the need for establishments to link clients and girls. Since girls can keep the major share of earnings if they do not work as full-time workers in establishments, they prefer to work outside establishments. For example, in Jhapa, when based in establishments, girls would, at most, get $40 \%$ of what the client pays; yet when they work outside the establishment, they would pay around $30 \%$ to the intermediary (who could still be the establishment owner) and keep the rest (70\%). Furthermore, this $30 \%$ is only payable for the first time the intermediary links a potential client; after the first contact, the girls no longer need to pay the intermediary for subsequent work with the same client. In Kathmandu, those engaged in street-based CSW only need to pay the hotel room charge, while those who engage in CSW through intermediaries pay around $10-15 \%$ to the intermediaries for the first time. From that point onwards, they negotiate with the clients themselves and earn more than when intermediaries are involved.

Despite this move to a more virtual world, AES establishments continue to play a role as platforms to kick start CSW-activities. The venues that comprise the AES in Nepal (dance bars, doharis, guest houses, cabin restaurants and massage parlours), as well as providing the services they overtly advertise, are also sites for CSW and where potential clients meet girls.

In cabin restaurants, $80 \%$ of girls were found to be engaged in CSW (Freedom Fund 2018), and our study found similar evidence. Respondents working in dance bars explained that sexual activities do not take place inside these bars though girls are expected to offer kissing, cuddling and intimate touching, and to watch pornography to 'entertain' guests. Sex services in such case are facilitated either by brokers-who are an important part of the CSW ecosystem and could be both male and female, ex-AES workers, young girls and boys currently in the AES, male partners of the girls as well as employers working in the AES venues-or the girls themselves directly arranging with potential clients for sexual activities to happen outside the bars. The bars make money through providing food and drinks at high prices; waitresses receive a percentage of money taken.

Dohari (meaning duet) restaurants provide singing, food and drinks but are also a place where sex can be solicited in similar ways either by brokers or by the girls themselves. Both in Dohari and dance bars, the girls are often expected to bring in clients, and their wages depend on the number of clients and how much each client spends in the venue. This eventually leads to CSW even if the girl does not first join a Dohari with the intent of engaging in CSW.

We are expected to bring clients. So, we call them and have to make them happy. They want us to sit with them when they are eating, and run their hands over our bodies. (IDI, adolescent working in a dohari)

In khaja ghars (small eateries), there are usually separate rooms at the back for CSW, and girls are expected to provide sex services. The financial transactions take place in-person between the employer and the client. However, once the girls know the 
clients, they can establish direct linkages with them through phones and can provide services outside khaja ghars.

Home-based sex work seems to be growing, with different modalities using digital technology to different extents. In one model, we found that an older woman (the 'keeper')—usually an ex-sex worker-would keep girls in a flat, operating it like a brothel, with clients coming to the flat or her sending girls to the clients who wanted to meet girls elsewhere. Negotiations with the clients are done by the keeper over the phone. The information about the client is given to the girls over the phone in cases where the girl does not live with the keeper. The keeper typically pays for the girls' food and accommodation and gives them a salary. In another model, girls meet clients through social media, and negotiations and transactions are carried out through phones and messages. In another instance, people who operate AES venues or hotels collect pictures from girls and when there is demand, send pictures of several girls to a potential client. After that, meetings and negotiations between the girls and the clients happen over the phone or through messaging applications such as Messenger.

\section{A Brief Background on Girls Working in the Adult Entertainment Sector in Nepal}

While earlier studies (Ministry of Women Children and Social Welfare 2008; Shakti Samuha 2008) found that girls working in the sector came from the surrounding hills of the Kathmandu valley, we found girls from many parts of Nepal now working in the AES in Kathmandu having come here primarily for study or work. In Jhapa and Sunsari girls have also migrated from surrounding rural areas of the district. Resonating with more recent studies (Freedom Fund 2018), we also found girls from high-caste groups who were not previously likely to engage in CSW now entering the sector due to peer-influence and networking through phone and social media.

Drivers for all kinds of girls to join the sector included: aspirations for a better life or for artistic success such as being a singer/dancer and/or performing abroad; poverty and deprivation (e.g. due to lack of economic support from fathers or husbands due to family disintegration); early marriage or marriage through elopement, with its associated loss of support structures; and easy of entry as academic qualifications or prior experience are not needed. Girls also entered the sector because it provided them with a daily cash income, flexible working hours to balance attending school/college or childcare. Boyfriends and partners also pulled girls into the sector by setting up clients for them and blackmailing the girls.

While still largely undertaken for money, girls from middle- and higher-income families, who shared that their family were well-established and could fund their needs, were also found to be engaged in CSW due to peer influence.

My parents are rich. They both have jobs and we have a house in Kathmandu. My parents can support me. But I came here with my friend. (IDI, adolescent girl, Jhapa)

Most of the girls are either school/college-attending or are dropouts with no other work experience. Some respondents reported having worked in construction, in cleaning jobs 
or as salesgirls in small clothing shops or grocery stores before coming to work in the AES.

\section{Technology Use and the Facilitation of Sex Work}

Smartphones and the internet are the most common technologies used by girls in the AES. Most girls have access to the internet either at home or in the workplace. Girls who do not work from establishments buy their own data pack. For girls undertaking home-based or street-based CSW, smartphones are the main medium of contact. There are also group chats where girls and clients meet. We did not find girls who were using laptops, tablets or computers for these purposes.

There are two distinct but interlinked features of the use of digital technology in this sector. The first one is to facilitate sex work and the second one is to build agency amongst girls working in the sector. We describe the two features separately.

\section{Use of technology in facilitating sex work}

Study respondents noted that previously, when girls worked through establishments, they used employers' landline phones to call clients, as requested by their employers, and they did not have their own mobile phone to chat and remain in contact with clients outside work. With mobile phones becoming much more common, girls now use them to keep in regular contact with clients outside the establishments. However, as mentioned above, after work in the AES venues, girls may provide sexual services to clients, and such arrangements are usually fixed over chats or phone calls directly between the girls and the clients.

Messaging is the most common means of chats for literate girls while those who are illiterate use voice chats or send picture clips when talking with clients. Girls who do freelance CSW often have two sim cards and create multiple IDs-for instance, using two IDs on Facebook (one for family and friends, and another for CSW to reach out to clients or to be visible in the CSW market). They were also found to have set up multiple Facebook accounts and are part of multiple IMO and Messenger groups for CSW only.

Girls also use mobile phone messaging and voice chats to maintain contact with clients who are either in India or abroad (Nepali migrants). Some girls are engaged in seasonal migration to India with such clients, while some girls reported receiving gifts and money from Nepali migrants who are working abroad.

Besides phone calls, our short study of a YouTube channel found that girls advertise themselves as models and sex workers either in their own YouTube channels or through interviews in other digital platforms (such as Pulchowki media).

Besides using YouTube or TV channels for linking to clients, our study of online chats showed that there are several online groups through IMO and Messenger, which are potentially used as platforms for CSW transactions. While there are no obvious dealings done online in such groups (except perhaps for some erotic photos), these are platforms for people to meet virtually, and once they have met, people 
then chat individually and the negotiation is done outside the group over personal online chats.

The chat groups consist of Nepali girls and boys as well as international members. Such chat groups can be establishment-based groups such as Hamro ramailo dohari (meaning it belongs to a dohari establishment), or just open platforms such as 'chatting with couple' or 'red light area', 'Filipino and Indonesian girls'. However, group chats on IMO are only possible for girls who can use text messages. For some groups, girls must know Hindi and some English. These chat groups are also used by intermediaries and boyfriends to contact clients for the girls who are illiterate. Once they meet on the group, the clients, intermediaries and girls can invite their friends, thus creating a virtual supply and demand chain. Girls then chat online through voice messaging or intermediaries, noting clients' requests, and supplying the girls to them.

Video making is a key part of the AES in Nepal, and in our sample, girls who work in doharis were more likely to engage in this. In some cases, girls invest money to produce a 'music video', hoping they would sing and play the lead role, but later realise it is a pornographic video for the internet. In other cases, girls are recruited to perform in pornographic videos, short movies, traditional and modern songs, or for photo-shoots (with pornographic content) that are then uploaded online. Respondents shared that in such cases, Facebook and Messenger groups are also ways to arrange these transactions. Video makers, who are another group of people involved in the AES ecosystem, approach girls working in the AES establishments and then use social media or phone calls to establish contact and recruit the girls for making pornographic videos.

Phone and social media are also used by potential recruiters and brokers who are an integral part of the CSW ecosystem. Potential recruiters and brokers use Facebook to reach out to new girls through their existing Facebook friendships with girls already in the AES. Potential employers also recruit girls already working in the sector through social media. Once they are engaged in CSW, other employers also get in touch with them through their mobile phones and via Messenger, and hence their market base expands.

As mentioned above, brokers can be male or female. Female brokers who currently live in urban areas, recruit girls from their home villages in rural areas through social media, befriending them through Facebook and Messenger, understanding their aspirations for city jobs or migration. When girls arrive in the urban areas, they first casually introduce them to employers or link them to clients seeking CSW services and later push girls into the sector. Such women keep regular contact with people back home to obtain information about girls who want to come to town for work and befriend them through mutual village-based connections.

Evidence from our study also shows that intermediaries outside of AES establishments (such as tourist guides and staff of recruitment agencies) recruit girls through phones as one-off assignments directly from school and college in Jhapa, Sunsari and Kathmandu, or through peer-to-peer networks, instead of going as clients into the establishments or keeping the girls as full-time employees. While recruitment does not happen online, phones are still critical in this transaction and information about the girls and initial contacts are often made online. 
This also applies for smuggling (as distinct from trafficking which is done without knowledge or is a forced condition) of girls to India and beyond. Girls aspiring to work in the AES in India and in the international AES choose to be smuggled (vs. those who are trafficked and don't have a choice) and the process is done via phone, chat and messages. The Nepali intermediaries give information or link girls to their Indian counterparts over phone or chat. All the follow-up processes and until the girls are collected in the Nepal border by an Indian vehicle, are done over phone and chats.

Girls voluntarily migrating to India seasonally to live as mistresses (where they are expected to provide sexual services and companionship to a single client who pays for their upkeep throughout their stay) also use phone and chats as a means for communicating all the necessary arrangements. Travel arrangements are done between the girl and the client over the phone and there are very few in-person meetings until the girl reaches the destination. Furthermore, when the girls return to Nepal, the Indian clients visit and stay with them. All the arrangements are done through phone and chat.

In our observation of the two border points, we also found that girls, particularly those who travel to India from the eastern part of Nepal for CSW, arrange for the employers or prospective clients to provide them with papers for 'networking' businesses. When they are checked by the border police in Nepal (a regular process girls have to go through), they tell the police that they are going for networking business training in India. All the arrangements (such as making necessary documents for trainings, invitation letters, and arrangement for pick-up vehicles) are done virtually. Indian employers might also fly girls from Kathmandu to the eastern border, from where they cross the border in employer-arranged private vehicles. In such cases too, all negotiations are done by phone after the employer has first met the girls faceto-face in Nepal.

For illiterate girls, boyfriends/partners create online identities (IDs) for them and negotiate with potential clients as middlemen.

\section{Use of Technology in Increasing Agency of Sex Workers}

Girls also use technology to maintain their network and get support from peers. Girls often work in groups once they know about each other. They chat amongst each other about their problems regularly. Such chats are also used to help each other including for: arranging meetings with new clients, exchanging clients (e.g. if a girl is tired and a client is asking her for service, they link the client to a friend who is available), exchanging information about clients and the market (e.g. which areas of the city are lucrative, which clients do not pay/are abusive and so dangerous), linking friends with new clients or intermediaries, and meeting or finding boyfriends. All these communications involved are carried out through messenger and IMO. 


\section{Why Existing Programmes are Leaving Some Girls Behind}

An analysis of reviews of 10 programmes on anti-trafficking and tackling CSW in Nepal shows that, except for one, existing interventions use an establishment-based outreach model. The social mobilisers reach out to girls first in the establishments, provide them with information about services and often distribute family planning materials, also using SRH issues as an entry point to convince employers. Once they have raised interest among the girls, which sometimes takes several visits, girls are asked to come to drop-in centres run by local NGOs, where the above-mentioned services are located. Once girls begin to attend the drop-in centres, they are more likely to keep in touch with the centres even if they do not attend sessions regularly.

Our case studies showed that young, mostly unmarried girls who work in the AES venues were keen to learn more singing and dancing skills, also to enable them to go abroad, so would come to the drop-in centres when training in these skills was available. They were also the most likely to attend sessions related to out-of-school education and tuition, especially if they were thinking of leaving CSW. Girl who are engaged in freelance work do not come to the programmes due to lack of information and fear of stigmatisation. Married girls with children usually want to leave the sector when they think their children are old enough to understand what their mothers are doing to make a living. They then attend livelihoods training sessions and other programming that provides seed money to assist with leaving the sector.

Since CSW is no longer exclusively mediated by establishments, establishmentbased outreach might be less effective to reach girls who are engaged in CSW on a freelance basis, therefore leaving behind a significant number of girls. Programmes need to adapt according to the changing trends and consider using different approaches, include virtual ones, as a medium for outreach. Sahara Nepal, a national NGO working with girls in the AES, has started using this approach in Jhapa and Sunsari. The NGO studied virtual groups and popular social media used by commercial sex workers, clients and intermediaries, and came up with certain characteristic features such as the local code words that are used by sex workers. They would scan for potential Facebook, Messenger and IMO groups, becoming an active chat member in such groups. They then used these links and information to send SMS messages around SRH and HIV prevention. According to key informants who worked in the programme, they were successful in raising awareness among freelance sex workers about the importance of seeking SRH and HIV prevention services and have convinced some to regularly go for HIV testing. They have also established a community HIV-testing model in Jhapa, have organised commercial sex workers into groups and organised regular meetings for them. As a result, many workers now come regularly to the centre just to catch up with workers or to ask about facilities, even though the donor-funded programme stopped a year ago (due to donor support ceasing). This programme has not been expanded to other districts due to unavailability of donor funding. 


\section{Conclusion}

The AES in Nepal is now made up of a complex web of venues, which includes establishment and non-establishment based, and includes those engaging in freelance as well as employed sex work. Many adolescent girls and young women are involved in the sector (along with men and boys, though they were not the focus of this article), and they perform a range of activities. Being involved in this sector means they can earn cash daily as well as earn more than what their experience and qualification might yield if they were employed in other sectors, fulfil their desires of becoming dancers and singers, and (for some) allow them to provide for their families and children.

CSW is increasingly mediated virtually, through mobile phones, the internet and social media, including YouTube and other video-hosting sites, either by sex workers themselves or by establishment owners, using mobile phones. While technology has not entirely displaced establishment based CSW, especially in Kathmandu, it has greatly expanded the sector and further enmeshed girls into risky jobs that have a negative impact on their physical and emotional wellbeing. Our study suggests that the 'virtualisation' of CSW has led to an underestimation of the numbers engaged in CSW in Jhapa, Sunsari and Kathmandu. There is no survey on the girls (and boys and people of other gender) working in the sector so far and estimates usually come from qualitative studies through the AES venues that use snowball methods to track respondents. While this can give some basis for data on girls working through AES venues, they leave out girls who are engaged in freelance sex work, work seasonally or part time as sex workers or who work through brokers who facilitate sex work through the establishments mentioned above as well as through the internet.

Technology is now being used by clients (to access girls), by brokers (to connect with and recruit girls into CSW), and by girls themselves to access clients; both within Nepal and across the border in India and elsewhere. Sometimes girls themselves might post videos and pornographic materials on the internet or set up/ become members of groups soliciting sex online. But, to date, these forms of sex work have not been included in studies estimating the numbers of girls involved in CSW. Hence, while we know it is a growing industry, we do not know what proportion of population we are talking about.

The study finds that while girls and other members of the CSW ecosystem (brokers, clients, employers) are using digital technologies, intervention programmes, except for a few, have not been able to catch up with the change. There is a danger of girls being left out from such programmes and this demonstrates the lack of preparedness from the part of government and support systems (programme interventions) to adapt and respond to changes in the CSW ecosystem. New programmes in the AES and for those engaged in CSW, including those focusing on education, physical, SRH and mental health services, should adapt to respond to girls who might be 
out of the reach of existing programmes. Programmes could provide services using digital technologies and perhaps move from a supply-driven to demand-driven way out. One area to cost-effectively use digital technology is in dissemination of information around future-risk and short termed outcomes for girls if they enter this sector. The other area is to raise awareness on available services that relates to alternate employment opportunities as well as trainings. If girls involved in AES know about the risks of being involved in this sector and where/how to seek support when needed, they are more likely to seek this support (again, using digital technology).

While some key informants noted that better monitoring of establishment-based venues will bring down the number of girls and boys working in the sector, alone it is not sufficient, given that much of CSW now takes place beyond establishments. Hence developing mechanisms to monitor and regulate this new form of virtual CSW, also needs to be considered. While this was not the focus of our study it remains to be seen whether this new form of CSW offers greater protection and control for girls engaged in CSW-or potentially brings even greater risks through the different forms of exploitation it enables.

Current programmes do not include activities to raise awareness about the risks of working in the AES in India and other international destinations. The study finds that there is a need for programmes to show the risks and challenges associated with working in the sector abroad, and to teach girls about alternative forms of work.

Finally, further evidence is crucial in raising awareness of the plight of girls working in this sector. While this study makes a contribution, gaps persist, both in quantitative and qualitative data. Further study would provide insights into the reasons behind any changes in trends - such as a decrease or increase of clients and employers and girls and boys working in the sector-as well as how technology is being used in the mediation of CSW. This evidence could then be used to inform policy and programmes, ensuring maximum impact.

\section{Appendix}

See Table 1. 
Table 1 Tools used for the study and the type and number of respondents in each site

\begin{tabular}{|c|c|c|c|c|}
\hline Tool & Total tools & Kathmandu & $\begin{array}{l}\text { Sind- } \\
\text { hupal- } \\
\text { chowk }\end{array}$ & $\begin{array}{l}\text { Jhapa } \\
\text { and } \\
\text { Sunsari }\end{array}$ \\
\hline Focus group discussions (FGD) & 26 & 11 & 10 & 5 \\
\hline FGD with school-going girls & & - & 1 & - \\
\hline FGD with school dropout girls & & - & 1 & - \\
\hline FGD with college-going boys & & - & 1 & - \\
\hline FGD with adult men & & - & 1 & - \\
\hline FGD with mothers of adolescent girls & & - & 1 & - \\
\hline FGD with CSWs (adolescent girls) & & - & 1 & 5 \\
\hline FGD with girls working in hotels/guest houses & & 1 & - & - \\
\hline FGD with girls working in dance bars & & 1 & 1 & - \\
\hline FGD with girls working in massage parlours & & - & 1 & - \\
\hline $\begin{array}{l}\text { FGD with girls working in dohari/rodhi ghar-(singing } \\
\text { restaurants) }\end{array}$ & & 4 & 1 & - \\
\hline $\begin{array}{l}\text { FGD with girls working in cabin restaurants (khaja ghar/ } \\
\text { bhansa ghar) }\end{array}$ & & 1 & - & - \\
\hline FGD with boys working in dance bars & & 1 & - & - \\
\hline FGD with boys working in dohari & & 1 & - & - \\
\hline FGD with boys working in dance clubs & & 1 & - & - \\
\hline FGD with boys working in lounge bar/pubs & & 1 & - & - \\
\hline FGD with boys working in cabin restaurants & & 1 & - & - \\
\hline SGD with dropout boys & & - & 1 & - \\
\hline Life history interviews (LH) & 9 & 6 & 3 & \\
\hline LH with girls working in dohari & & 2 & - & - \\
\hline LH with girls working in dance bar & & 1 & - & - \\
\hline LH with CSW (freelance) & & 1 & - & - \\
\hline LH with girl working in massage parlour & & 1 & - & - \\
\hline LH with girls working in cabin restaurants & & & - & - \\
\hline LH with girls staying at rehabilitation centres & & - & 3 & - \\
\hline LH with girl working in a party-venue(banquet) & & 1 & - & - \\
\hline Case studies (CS) & 3 & 1 & 2 & - \\
\hline Key informant interviews (KII) including one employer & 45 & 32 & 8 & 5 \\
\hline In-depth Interviews (IDI) & 40 & 21 & - & 19 \\
\hline IDI with girls working in Dohari & & 2 & - & - \\
\hline IDI with girls working in dance bar & & 4 & - & - \\
\hline IDI with commercial sex worker & & 6 & - & 19 \\
\hline IDI with girls working in massage parlour & & 3 & - & - \\
\hline IDI with girl working in café & & 1 & - & - \\
\hline IDI with girl working in cabin restaurant (Khaja Ghar) & & 1 & - & - \\
\hline $\begin{array}{l}\text { IDI with rehabilitated girls running their own business } \\
\text { (beauty parlours/grocery shops) }\end{array}$ & & 3 & - & - \\
\hline IDI with boy working in a night club & & 1 & - & - \\
\hline
\end{tabular}




\section{Declarations}

Conflict of interest On behalf of all authors, the corresponding author states that there is no conflict of interest.

Open Access This article is licensed under a Creative Commons Attribution 4.0 International License, which permits use, sharing, adaptation, distribution and reproduction in any medium or format, as long as you give appropriate credit to the original author(s) and the source, provide a link to the Creative Commons licence, and indicate if changes were made. The images or other third party material in this article are included in the article's Creative Commons licence, unless indicated otherwise in a credit line to the material. If material is not included in the article's Creative Commons licence and your intended use is not permitted by statutory regulation or exceeds the permitted use, you will need to obtain permission directly from the copyright holder. To view a copy of this licence, visit http://creativecommons.org/licen ses/by/4.0/.

\section{References}

Basnett, Y., G. Henley, J. Howell, H. Jones, A. Lemma, and P.R. Pandey. 2014. Structural economic transformation in Nepal: A diagnostic study submitted to DFID Nepal. London: Overseas Development Institute.

Campbell, R., T. Sanders, J. Scoular, J. Pitcher, and S. Cunningham. 2018. Risking safety and rights: Online sex work, crimes and 'blended safety repertoires.' The British Journal of Sociology 70 (4): 1539-1560.

Center for Research on Environment, Health and Population Activities (CREHPA). 2001. A situation assessment of sex workers in Kathmandu valley: A focused ethnographic study. Kathmandu: CREHPA.

Central Bureau of Statistics (CBS). 2019. Report on the Nepal Labour Force Survey, 2017/18. Kathmandu, Nepal: National Planning Commission (NCP), CBS.

Cunningham, S. and G. de Angelo. 2017. Signals, screens and vertical differentiation: The case of commercial sex work. Presented at COST Prospol conference on Displacing Sex for Sale, 29-31 March, University of Aalborg, Copenhagen.

Cunningham, S., and T.D. Kendall. 2011. Prostitution 20: The changing face of sex work. Journal of Urban Economics 69 (3): 273-287.

CWIN\&ECPAT Luxembourg. 2015. Preparatory study for situational analysis of commercial sexual exploitation of children in Nepal: A preliminary report.

Dank, M., K. Vincent, A. Hughes, N. Dhungel, S. Gurung, and O. Jackson. 2019. Prevalence of minors in Kathmandu's adult entertainment sector. Kathmandu, Nepal: Freedom Fund.

de Zwager, N., and R. Sintov. 2017 Maximizing the development impact of migration in Nepal: Comprehensive market study. Kathmandu: International Organization for Migration (IOM), Institute for Integrated Development Studies (IIDS), International Agency for Source Country Information (IASCI) IOM Development Fund.

Frederick, J., M. Basnyat, and J. Aquettant. 2010. Trafficking and exploitation in the entertainment and sex industries in Nepal: A handbook for decision makers. Kathmandu Nepal: Terre des hommes Foundation.

Gioli, G., A. Maharjan, and M. Gurung. 2017. Neither heroines nor victims: Women migrant workers and changing family and community relations in Nepal. New York: UN Women.

Ibegbulam, I.J., C.C. Akpom, F.N. Enem, and D.I. Onyam. 2018. Use of the internet as a source for reproductive health information seeking among adolescent girls in secondary schools in Enugu, Nigeria. Health Information and Libraries Journal. 35 (4): 298-308.

Jones, A. 2015. Sex work in digital era. Sociology Compass 9 (7): 558-570.

Liechty, M. 2005. Carnal economies: The commodification of food and sex in Kathmandu. Cultural Anthropology 20 (1): 1-38. 
Livingstone, S., A. Nandi, S. Banaji, and M. Stoilova. 2017. Young adolescents and digital media Uses, risks and opportunities in low- and middle-income countries: A rapid evidence review. London: Overseas Development Institute (ODI).

MacPhail, C., J. Scott, and V. Minichiello. 2015. Technology, normalisation and male sex work. Culture, Health and Sexuality 17 (4): 483-495.

Maiti Nepal. 2010. Youth led study on the vulnerability of young girls working in restaurants, bars and massage parlors in Kathmandu. Kathmadu: Maiti Nepal.

Ministry of Women, Children and Social Welfare. 2008. Study about cabin, dance restaurants and massage parlours. Kathmandu: Government of Nepal, Ministry of Women, Children and Social Welfare.

National Human Rights Commission (NHRC). 2010. Trafficking in persons (especially on women and children) in Nepal. National Report, 2008-2009. Kathmandu: NHRC.

Onyima, J.K., and C.F. Egbunike. 2019. Smart phone is a expectation-laden trophy: Adolescent girlsadults' mobile phone tensions and changing sexuality negotiation. Journal of Youth Studies 22 (6): 729-751.

Paudel, K.P., S. Tamang, and K.K. Shrestha. 2014. Transforming land and livelihood: Analysis of agricultural land abandonment in mid hills of Nepal. Journal of Forest and Livelihood 12 (1): 11-19.

Poudel, M., and Y. Luintel. 2003. Strategies and practices of advocacy: Gender advocacy against trafficking in women in Nepal. Occasional Papers in Sociology and Anthropology 8: 59-76.

Powell, Mary Ann, Taylor, Nicola, Fitzgerald, Robyn, Graham, Ann, Anderson, Donnah. 2013. Ethical research involving children. Innocenti PublicationsUNICEF Office of Research - Innocenti, Florence

Raju, D., and J. Rajbhandari. 2018. Youth employment in Nepal. Washington, DC: International Bank for Reconstruction and Development/The World Bank.

Rand, H.M. 2019. Challenging the invisibility of sex work in digital labour politics. Feminist Review 123 (1): 40-55.

Richardson, D., N. Laurie, and M. Poudel. 2016. Women and citizenship post-trafficking. The case of Nepal. The Sociological Review. 64 (2): 329-348.

Risal, S., E. Hacker, and Sutra. 2018. Minors in Kathmandu's adult entertainment sector: What is driving demand? Kathmandu: Freedom Fund

Safer Migration Project (SaMi)/HELVETAS Swiss Intercooperation Nepal. 2018. Journey of a lifetime: A study on women and girls migrating for work in entertainment businesses. Lalitpur: SaMi/HELVETAS Swiss Intercooperation Nepal.

Sanders, T., L. Connelly, and L. Jarvis King. 2016. On our own terms: The working conditions of internet-based sex workers in the UK. Sociological Research Online 21 (4): 1-14.

Scott, J., V. Minichiello, and J. Meenagh. 2015. Male escorts in Australia. In Men who sell sex: Global perspectives, ed. P. Aggleton and R. Parker. London: Routledge.

Serriere, N. and Centre for Economic Development and Administration (CEDA). 2014. Labour market transitions of young women and men in Nepal. Work4Youth Publication 12. Geneva: International Labour Office.

Shakti Samuha, Free the Slaves. 2008. A study on the condition of slavery among women and girls employed in the restaurants and massage parlours of Kathmandu Valley. Kathmandu: Shakti Samuha

Stonard, K.E., E. Bowen, T.R. Lawrence, and S.A. Price. 2014. The relevance of technology to the nature, prevalence and impact of adolescent dating violence and abuse: A research synthesis. Aggression and Violent Behaviour. 19 (4): 390-417.

The Freedom Fund. 2019. Central Nepal annual report 2018. Kathmandu: The Freedom Fund.

The Freedom Fund. 2018. Central Nepal annual report 2017. Kathmandu: The Freedom Fund.

Zelezny-Green, R. 2018. Now I want to use it to learn more: Using mobile phones to further the educational rights of the girl child in Kenya. Gender and Development. 26 (2): 299-311.

Publisher's Note Springer Nature remains neutral with regard to jurisdictional claims in published maps and institutional affiliations. 